\title{
EVASÃO NAS UNIDADES DE ACOLHIMENTO: DISCUTINDO SEUS
} SIGNIFICADOS

\author{
EVASIÓN DE LAS UNIDADES DE ACOGIDA: DISCUSIÓN ACERCA DE SUS \\ SIGNIFICADOS \\ EVASION IN THE SHELTER UNITS: DISCUSSING THEIR MEANINGS \\ Adriana Guerra Abreu Lemos, Mayara Muniz Bastos Moraes, Daniel Gonçalves Alves, \\ Elizabeth Espindola Halpern e Ligia Costa Leite \\ Universidade Federal do Rio de Janeiro, Rio de Janeiro/RJ, Brasil
}

\section{RESUMO}

Este artigo discute os significados da evasão de adolescentes de duas unidades de acolhimento, tanto para estes quanto para os profissionais. Para isso, explicitam-se os pontos de vista de ambos, a fim de compreender como vivenciam e lidam com tal processo. Para a discussão do tema, foram analisadas 30 entrevistas com adolescentes e 47 com profissionais, utilizando a abordagem qualitativa, além de observações de campo. A coleta das entrevistas foi baseada na história oral e a análise, na teoria da comunicação. Pôde-se concluir que a falta de capacitação e supervisão dos profissionais afeta o processo de acolhimento dos jovens e também causa sofrimento psíquico aos cuidadores. Por fim, observou-se a necessidade de desenvolver um trabalho consistente e integrado com as equipes em torno dos verdadeiros objetivos das unidades de acolhimento, dando a elas suporte psicossocial.

Palavras-chave: evasão; adolescente; cuidador; unidade de acolhimento.

\section{RESUMEN}

Este artículo discute el significado de la evasión de los adolescentes, de dos unidades de acogida, tanto para estos como para los profesionales. Para eso, se expondrán la opinión de ambos para comprender mejor su experiencia y la manera que maneján este proceso. Para una discusión sobre el tema, se analizaron 30 entrevistas con adolescentes y 47 com profesionales, con enfoque cualitativo, y observaciones de campo. La colecta de entrevistas se basa en la historia oral y el análisis, en la teoría de la comunicación. Se concluyó que la falta de formación y supervisión de los profesionales afecta el proceso de acogida de los jóvenes y también causa malestar psicológico a los cuidadores. Se percibió la necesidad de desarrollar um trabajo, coherente y integrado con los equipos en torno de las verdaderas intenciones de las unidades de acogida, con el apoyo psicosocial.

Palabras clave: evasión, adolescente, cuidador, unidad de acogida

\begin{abstract}
This article discusses the meanings ofteenagers'evasion according to both the latter and professionals from two shelter units. In order to do this, the points of view of both of them carefully expressed, to comprehend how they live and deal with this process. In order to discuss the theme 30 interviews with teenagers and 47 with professionals were analyzed using the qualitative approach as well as field research. The interviews were performed based on the oral history, and the analysis was based on the theory of communication. It was possible to conclude that the professional lack of training and supervision affects the process of caretaking the youngsters and it also causes psychic suffering to the caretakers. Lastly, it was observed the need to develop a consistent and integrated work with the teams around the true objectives of the shelter units through a psychosocial support.
\end{abstract}

Keywords: evasion; teenager; caretaker; shelter unit. 


\section{Introdução}

O presente estudo se propõe a discutir os significados da evasão, tanto para os adolescentes, quanto para os profissionais que trabalham em unidades de acolhimento (UAs). Esse é um tema constante no cotidiano das UAs, geralmente sendo considerado pelos profissionais como um dos maiores empecilhos à realização do trabalho de acolhimento. No entanto, suas causas, impactos e significados raramente são debatidos.

Nesta oportunidade, pretende-se ampliar o entendimento que se tem a respeito do ato da evasão como um problema a ser superado, analisando como ele é compreendido por cada sujeito. Acredita-se que a evasão seja uma experiência singular cujos significados não podem ser generalizados. Para tal, serão investigados tanto os pontos de vista dos profissionais, quanto os dos adolescentes sobre o tema. Com isso, espera-se contribuir para que esse assunto venha a ser mais estudado e debatido, ajudando os profissionais das UAs a encontrarem diferentes formas de manejálo, a fim de que o processo de acolhimento possa de fato ser uma experiência de proteção e potencialização na vida dos adolescentes.

As medidas de proteção para adolescentes são aplicadas quando seus direitos, previstos no Estatuto da Criança e do Adolescente - ECA (Lei Federal 8.069, 1990), forem ameaçados ou violados por ação ou omissão da sociedade ou do Estado; por falta, omissão ou abuso dos pais ou responsável; em razão de sua conduta (Lei Federal 8.069,1990). Dentre elas encontra-se o acolhimento institucional, que será foco deste estudo. Tal medida possui caráter provisório e excepcional, como forma de transição para a reintegração familiar e comunitária. Tem como principais objetivos o cuidado, a proteção, a garantia de direitos como lazer, educação, saúde, convivência comunitária, apoio social e psicológico, além da preparação do adolescente para o retorno à família.

Dentre os princípios norteadores para o trabalho nas unidades de acolhimento institucional, previstos no artigo 92 do ECA (Lei Federal 8.069, 1990), estão:

I - preservação dos vínculos familiares e promoção da reintegração familiar;

II - integração em família substituta, quando esgotados os recursos de manutenção na família natural ou extensa; grupos;
IV - desenvolvimento de atividades em regime de co-educação;

V - não desmembramento de grupos de irmãos;

VI - evitar, sempre que possível, a transferência para outras entidades de crianças e adolescentes abrigados;

VII - participação na vida da comunidade local;

VIII - preparação gradativa para o desligamento;

IX - participação de pessoas da comunidade no processo educativo.

Dessa forma, também segundo o documento Orientações Técnicas: Serviços de Acolhimento para Crianças e Adolescentes (Conselho Nacional de Defesa da Criança e do Adolescente - CONANDA \& Conselho Nacional de Assistência Social - CNAS, 2009), que regulamenta a organização e oferta desses serviços para crianças e adolescentes no âmbito da política de Assistência Social, é fundamental que a abordagem inicial seja afetuosa e não represente uma revitimização do adolescente; que haja uma equipe de profissionais capacitada para recebê-lo; espaço físico adequado; além de fluxo de comunicação eficiente entre a rede socioassistencial.

Durante o período de acolhimento, é fundamental que $o$ atendimento seja personalizado, garantindo assim que a história de vida e subjetividade do adolescente sejam norteadores do trabalho e dos encaminhamentos a serem feitos. O documento citado acima ressalta ainda a relevância da construção de vínculos entre profissionais e adolescentes, favorecendo assim o diálogo e criando um ambiente continente para o desenvolvimento adequado destes.

Deste modo, conforme ressalta Andrade e Morato (2004), essa seria uma prática psicológica que se inclina para acolher o sofrimento humano, entendido aqui como perda de sentido, comprometendo-se com a atenção e cuidado, para que o sujeito se conduza na direção de seu bem-estar.

Para Costa (2010), acolher seria um ato receptivo, que reconhece o indivíduo como sujeito que tem voz, levando em conta seu ponto de vista. Logo, o acolhimento só acontece através do encontro.

Os resultados aqui exibidos pretendem trazer à discussão o ponto de vista de cuidadores e adolescentes que foram entrevistados entre 2008 e 2010 , em uma pesquisa qualitativa, que buscava investigar aspectos das relações entre cuidadores e adolescentes de unidades de acolhimento municipais e, dentre esses aspectos, o tema da evasão foi bastante significativo. 


\section{Método e campo}

Para este artigo, partiu-se da hipótese inicial de que a evasão, por ser uma experiência singular, tem mais de um significado e que, sendo parte do processo de acolhimento, ela não significa uma interrupção do mesmo.

Para a coleta dos dados, foram feitas observações de campo e entrevistas semi-dirigidas com 30 adolescentes em cinco UAs e com 47 profissionais em duas UAs. Foram entrevistados seis adolescentes em cadaUA(que serão denominadas UA1, UA2,UA3, UA4 e UA5), 21 profissionais na UA1 e 26 na UA2, sendo adicionados nomes fictícios a todos os participantes. Todos assinaram o Termo de Consentimento Livre e Esclarecido e a pesquisa foi aprovada pelo Comitê de Ética em Pesquisa local e pelo CONEP - Comissão Nacional de Ética em Pesquisa/MS.

Três unidades de acolhimento apresentadas neste estudo atendiam exclusivamente adolescentes do sexo masculino, com idade entre 12 e 18 anos incompletos. As demais atendiam adolescentes de ambos os sexos, também com idade entre 12 e 18 anos incompletos. Estes eram recebidos mediante encaminhamento do Centrais de Recepção, Juizados ou Conselhos Tutelares. A maioria deles tinha passagens anteriores por outras UAs e pelas ruas, sendo apenas 10 encaminhados por solicitação da família e estavam sob medida de proteção pela primeira vez. Os motivos para o acolhimento eram os mais diversos, destacando-se a dificuldade de relacionamento entre adolescentes e suas famílias e o envolvimento com tráfico de drogas.

As cinco unidades possuíam rotinas semelhantes de trabalho, como as atividades relacionadas à escola, à saúde e, esporadicamente, atividades de lazer, visando ao retorno à vida social. Cada unidade de acolhimento atendia, à época, em torno de 15 a 20 adolescentes, não sendo possível precisar um número devido à grande rotatividade.

Os profissionais entrevistados, de ambos os gêneros, ocupavam um dos três tipos de funções nessas instituições: equipe técnica (acompanhamento técnico e judicial da medida, estudo técnico, atendimento psicológico e de assistência social, elaboração de relatórios), educadores sociais (acompanhamento das atividades diárias dos adolescentes, como ida à escola, ao médico, higiene pessoal, atividades educativas e de lazer, quando havia) e equipe de apoio (apoio à equipe técnica, organização e manutenção da unidade de acolhimento: limpeza, preparação das refeições). O corpo técnico das UAs1 e 2, à época das entrevistas, era constituído por uma psicóloga e três assistentes sociais, além da diretora, que trabalhavam de segundafeira a sábado. O corpo de educadores era composto por uma média de dois a três educadores por plantão diurno e noturno (apenas os educadores tinham regime de plantão). Destaca-se que, à época das entrevistas, a equipe da UA2 trabalhava em conjunto há mais de cinco anos, sendo mais articulada nos encaminhamentos e procedimentos. Já na UA1, por conta da maior rotatividade de profissionais, a equipe era menos coesa.

Para a coleta das entrevistas, construiu-se um roteiro semiestruturado (Minayo, 2006) para que eles pudessem contar livremente suas histórias pessoais e profissionais, utilizando-se o método da história oral por conter uma vivacidade, "um tom especial", característico de documentos pessoais (Alberti, 2004). Thompson (1992), um precursor na utilização do referido método, defende que a evidência oral transforma os "objetos" de estudo em "sujeitos", contribuindo para uma história não só mais rica, mais viva e mais comovente, mas também mais verdadeira. Lozano (2006) privilegia o emprego dessa metodologia por acreditar que, pelo fato de ela fazer aflorar um conteúdo que advém de fontes inéditas, ajuda a situar os indivíduos como sujeitos de suas vidas.

A análise do material foi baseada na Teoria da Comunicação, pelo método da abdução proposto por Boudon (1998), para articular, através das narrativas dos profissionais, as vivências objetivas/subjetivas. O método da abdução em comunicação evidencia as estruturas de pensamento do narrador, ressaltando os temas e analisando-os por uma alternância argumentativa. As categorias-base, delimitadas a partir das hipóteses da pesquisa, geram estes temas que vão dialogar com as pistas abduzidas das narrativas para tratamento dos dados, criando uma rede para análise, não hierárquica ou linear. Tais pontos são organizados e articulados entre si em um diagrama-síntese, denominado pelo autor de templum.

A categoria base de cada templum é mediatizada por duas metacategorias, uma positiva e outra negativa. A análise inicia-se a partir de um tema que é induzido. Deste, deduz- se uma hipótese para esta categoria e, finalmente, como prova, abduzem-se pistas emergidas das narrativas, deixando evidente o que antes estava implícito e podendo revelar novos fatos. Depois é feita uma verificação a partir de novos argumentos com uma tese e uma antítese que, por fim, vão gerar a síntese da análise deste templum, que pode ou não comprovar a hipótese inicial.

Após a transcrição das entrevistas, as categoriasbase que emergiram como as mais significativas foram agrupadas em unidades temáticas, considerando que 
o objetivo central deste artigo era entender como os profissionais e os adolescentes vivenciavam a evasão. Foram elas: Rua e seus atrativos; Vivências dos profissionais; e Processo de Acolhimento. A questão da evasão perpassa todos os temas de análise das três categorias-base.

\section{Resultados e discussão}

A questão da evasão foi um elemento que surgiu nas falas dos profissionais, de forma recorrente, mostrando, assim, sua importância no cotidiano das UAs. A partir disso, pôde-se abduzir como o constante movimento de entrada e saída tem diferentes significados, tanto para eles, quanto para os adolescentes. A evasão, geralmente, não é vista pelos jovens como algo negativo. Por outro lado, os cuidadores a percebem como uma interrupção nociva ao progresso do seu trabalho e, por vezes, até mesmo como um retrocesso. Faz-se necessário, então, analisar os dois pontos de vista, buscando compreender qual o entendimento que cada um deles possui sobre a evasão e como lidam com ela.

\section{A rua e seus atrativos}

Foi percebido que cuidadores e adolescentes têm visões diferentes sobre a rua. Isso se dá devido às suas experiências de vida marcadas por fatores diversos, fazendo com que eles tenham percepções muitas vezes opostas sobre esse espaço. De modo geral, os profissionais entrevistados compartilhavam do senso comum da sociedade que considera a rua como um local de perdição, perigo, que afasta os adolescentes de uma vida regrada e correta, segundo pensamento predominante desde o início do século XX (Esteves, 1989). Já para a maioria dos adolescentes entrevistados, sobretudo para aqueles que já experienciaram viver nas ruas, ela representa uma sensação de liberdade, de distanciamento dos problemas, das regras da UA ou de sonhar com uma vida diferente. Destaca-se que vinte adolescentes entrevistados já possuíam mais de uma passagem por UAs e dez foram abrigados pela família, no entanto, destes, oito foram para as ruas após passagem pelas UAs, intercalando sua estadia nelas com passagens pela sua casa e pelas ruas.

A atração pelas ruas seria, de acordo com os profissionais, um dos motivos para a evasão dos adolescentes. João do Rio (1908/2007, p. 5) nos esclarece o encanto que ela possui:

Para compreender a psicologia da rua não basta gozarlhes as delícias como se goza o calor do sol e o lirismo do luar. É preciso ter espírito vagabundo, cheio de curiosidades malsãs e os nervos com um perpétuo desejo incompreensível, é preciso ser aquele que chamamos de flaneur e praticar o mais interessante dos esportes - a arte de flanar.

As ruas podem trazer atrativos imediatos aos adolescentes, como o fácil acesso às drogas e encontrar os amigos, como relatam os profissionais, fugindo assim do "caminho certo" que a UA oportunizaria:

O problema da evasão está dentro de cada um deles. Eles tão sempre evadindo, buscando o caminho das drogas. Eles têm tudo: uma palavra legal, aqui dentro, uma palavra de conforto e caminhos bons. Mas, às vezes, eles começam a ficar 'fissurados'. É por causa de droga! Ai, querem evadir, evadem e se juntam com outros lá fora. (Pedro, equipe de apoio, UA2)

Já um dos adolescentes, quando perguntado o que mais the atraia nas ruas, respondeu:"Andar na cidade. Sair aqui é foda. Dia de saida é só no sábado e, pôxa, até seis da tarde; depois, tem que chegar e não vai sair mais, que isso?" (Cláudio, 16 anos, UA5)

Nas ruas eles criam suas próprias regras, respeitando-as, diferente do que ocorre nas UAs, cujas regras não acatam, pois não participam de suas definições. Por isso, têm dificuldade em se manter na instituição, já que fora dela têm mais liberdade de fazer o que desejam. Assim, sentem-se desrespeitados, por serem repreendidos e obrigados a seguir normas instituídas pela sociedade:

Eu gostava mais da rua. Me sentia melhor na rua. Eu podia usar droga, podia sair, podia dormir a hora que eu quisesse, acordar a hora que eu quisesse, podia comer a hora que eu quisesse. No abrigo tem regras. (Amanda, 13 anos, UA3)

A dificuldade dos adolescentes em se adequar às regras é confirmada pela profissional abaixo:

A questão da disciplina, dos horários, das regras, também é um grande desafio pra eles. Alguns enfrentam, outros não suportam. Depende do tempo de permanência na rua. Aqueles que estão há muito tempo na rua têm uma dificuldade maior de se enquadrar nesse contexto do abrigo. E, ai, evadem. (Joana, psicóloga, UA2)

Para ela, o fato de permanecer mais tempo na rua dificultaria o respeito às regras da UA. Todavia, essa psicóloga, bem como a maioria dos profissionais entrevistados, não percebe que uma rotina repleta de regras para qualquer procedimento não faz sentido aos olhos do adolescente, visto que nas cinco UAs ela é imposta sem um diálogo que o faça compreendêla, para assim aceitá-la. Como o próprio documento Orientações Técnicas: Serviços de Acolhimento para 
Crianças e Adolescentes (CONANDA \& CNAS, 2009) afirma, as regras precisam ser construídas em parceira entre profissionais e adolescentes, para que sejam cumpridas dentro de um consenso.

No que diz respeito à relação de tais adolescentes com a escola, fica patente que muitos não conseguem se amoldar aos padrões pedagógicos hegemônicos, sobretudo porque a própria estrutura escolar não está preparada para acolhê-los. Ela não consegue lidar com as dificuldades desses alunos de se adaptarem às suas regras, padrões e expectativas. Eles evadem da vida escolar, acentuando os sentimentos de rejeição e de menos-valia, e optam pelas atividades lúdicas, conforme demonstra o fragmento da entrevista abaixo:

\begin{abstract}
A gente está com uma grande carência dos meninos na escola. Os meninos não frequentam a escola de jeito nenhum. E é só a garotada nova. Às vezes, em vez de ir pra escola, eles vão soltar pipa, eles vão namorar. Aquela coisa mesmo de criança. E isso está complicado, está deixando muito insatisfatório o nosso trabalho. Eles tão indo pra escola, mas não têm uma motivação. Então, eles acabam abandonando, desistindo. (Marcus, educador social, UA2)
\end{abstract}

Vale ressaltar que, além de eles não permanecerem na escola, os estágios oferecidos pelas UAs, na verdade, não os profissionalizam, pois, geralmente, são tarefas mecânicas, que não trazem novos conhecimentos, nem qualquer desafio ou satisfação a eles, reforçando sua condição de desafiliados (Castel, 1998). Trata-se de um trabalho de modelagem social (Foucault, 1984) que nem sempre o adolescente está disposto a se submeter, frequentemente reagindo com agressividade, desobediência e fuga.

Os 47 profissionais entrevistados acreditam que a permanência dos adolescentes na UA é sinônimo de proteção, visto que a rua, como já dito, contém uma série de fatores negativos que os desencaminhariam. Já a maioria dos adolescentes não veem a instituição como um local de acolhimento, mas sim de aprisionamento, já que têm de seguir os padrões impostos nos quais há poucas chances de fazerem as próprias escolhas.

Percebe-se que há desmotivação e falta de habilitação para os profissionais lidarem com as situações que se apresentam, como a evasão, fechando-se à sua visão e seguindo um método de disciplinamento que não se torna efetivo aos adolescentes. Assim, as UAs acabam não proporcionando a eles um ambiente adequado para o seu desenvolvimento (Lei Federal 8.069, 1990). Já o adolescente, diante de tantas exigências pouco interessantes e não conseguindo corresponder ao que lhe é demandado, acaba por evadir.
Ressalva-se que não são todos os adolescentes que evadem das UAs. Por ser um movimento singular, ele tem variações. Não necessariamente um adolescente com mais de uma passagem por UAs e pela rua evade mais do que aqueles que não possuem um histórico de passagem pelas ruas. Ao se referirem a quantas UAs passaram, pôde-se constatar que havia uma grande circularidade pela rede de acolhimento, demonstrando que o acolhimento podia se configurar como uma nova institucionalização nos moldes dos internatos do passado. Não foi observado nas entrevistas um padrão para as evasões, pois este não era o foco da pesquisa, por isto a frequência e o período que ficavam evadidos variavam para cada adolescente.

Dessa forma, também se torna mais complicada a criação de vínculos de afeto, o que contribuiria para a permanência dos adolescentes por laços com os profissionais da instituição e não por determinações alheias a eles.

Este panorama de inconsistências acaba confirmando a experiência de abandono, objetiva e subjetiva, e falta de acolhimento efetivo por parte das UAs. O adolescente, desestimulado a permanecer na UA, sente-se mais atraído a flanar pelas ruas.

Faz-se necessária a criação de espaços de diálogo nas UAs, que permitam a ambos os atores a exposição dos seus pontos de vista e a possibilidade de entendimento do outro, e o acolhimento efetivo, levando em conta suas singularidades e experiências de vida, desconstruindo visões cristalizadas sobre a rua.

\section{Vivências dos profissionais}

Pelo que foi constatado nas entrevistas, os profissionais entrevistados nas duas UAs lutam para manter seu equilíbrio emocional no cotidiano do trabalho. As experiências a que são submetidos são suficientes para desencadear situações emocionais com as quais eles, muitas vezes, não sabem lidar. Uma delas ocorre quando há evasão, que por vezes desperta neles o sentimento de trabalho perdido, quando não conseguem impedi-la. Frustrados, têm a sensação de que o seu trabalho não foi suficientemente útil. Além da noção de perda, alguns cuidadores a associam a outros aspectos, como, por exemplo, falta de inteligência dos adolescentes para serem "ajudados":

Eles saem por burrice! Porque aqui eles têm comida, roupa lavada, cama para dormir, tudo arrumadinho! Têm pessoas para orientar, têm os educadores da noite, têm os educadores do dia. Todo mundo trabalha direitinho, dentro do respeito. Lógico que têm horas que tem que apertar um pouquinho, porque se deixar.. Eles não são fáceis! (Paulo, equipe de apoio, UA1) 
A permanência na UA equivale para eles ao êxito profissional; já a evasão prediz fracasso e um futuro desolador para os adolescentes que não aceitam o trabalho da forma como é dado por esses profissionais. O sentido de "dar" é justamente aquele que o jovem não quer aceitar, pois o coloca numa posição passiva de receptor e não em uma ativa e de sujeito. Caso o trabalho de reinserção fosse desenvolvido junto com ele, discutindo-se cada etapa e fazendo-o participar efetivamente das decisões, o adolescente assimilaria melhor a proposta. Abaixo se tem um exemplo de um adolescente que não sustentou o retorno à família:

A evasão mexe! Porque eu acho que é um trabalho perdido. Cada vez que eles vão, quando voltam têm que recomeçar tudo de novo. Teve um que tava já estagiando direitinho, indo pra escola. Ele saiu daqui pra ir pra casa, de tão bem que ele já estava! E ele ficou só um mês no estágio, porque parece que ele acabou roubando. Foi mandado embora e ficou na rua. E, um dia, o educador falou assim: "Fulano tá naquele sinal ali, limpando vidro”. Ai, depois, eu passei num dia até chuvoso, eu vi aquela cabecinha levantar.. Eu falei: "eu não vou nem falar com ele porque senão eu vou chorar". (Renata, equipe de apoio, UA2)

A profissional abaixo relata a dualidade de sentimentos perante seu trabalho, ambiguidade esta compartilhada pela maioria dos entrevistados, e demonstra a sensibilidade para saber respeitar as escolhas e o tempo de amadurecimento de cada adolescente:

É muito prazeroso o trabalho e muito frustrante, ao mesmo tempo. São muitos os casos de insucesso, muitas perdas que a gente tem desses meninos ao longo do nosso trabalho. As vezes, a gente perde; daqui a pouco, recupera de novo. As vezes, ele não tá no momento de aderir a nada mesmo. Aí, a gente projeta demais, espera demais, sufoca o garoto de atividades, de expectativa. (Diva, assistente social, UA1)

Pode-se notar que tal profissional, uma exceção entre os entrevistados, faz a reflexão de que o tempo do adolescente é diferente do seu, porém, ainda assim ela se angustia com as "perdas" ao longo do percurso, devido às expectativas que cria. De fato, essas são projeções que o meio deposita nos indivíduos, representando aquilo que é tido como o melhor, o correto e o aceitável. Ou o adolescente se encaixa de forma obediente e resignada e o cuidador se sente bem sucedido; ou ele se rebela, geralmente evadindo, e o cuidador se sente fracassado.

Outra profissional destaca a importância da autonomia nas escolhas que o adolescente deve ter, mesmo que, segundo o ponto de vista da cuidadora, elas não correspondam ao que ela entende como sendo a melhor opção:

\begin{abstract}
Aqui, a gente suporta isso, essas idas e vindas do menino. É bem angustiante lidar com isso; a gente sempre acha que o que a gente faz depende da gente, depende do técnico. Mas não, depende também daquele menino, que é um sujeito que escolhe as coisas, que pode escolher, de uma maneira meio confusa, meio torta. Mas ele consegue escolher e dar um direcionamento para algumas coisas, que nem sempre é o que a gente quer, nem sempre é o padronizado. A gente tem que suportar, e isso é angustiante! (Márcia, assistente social, UA 2)
\end{abstract}

Faz-se importante, então, amparar o adolescente que está aprendendo a trilhar seu próprio caminho, uma aprendizagem que implica em cometer erros e acertos, aspecto que é inerente ao processo de desenvolvimento humano. E, mais do que isso, compreender que não é possível ter um método padrão a ser aplicado igualmente a todos e que trará, automaticamente, bons resultados. É preciso que os profissionais tenham uma visão mais ampla sobre a evasão e que estejam preparados para avaliar qual é a melhor estratégia de lidar com os adolescentes, respeitando sua subjetividade e história de vida. Para isso, faz-se necessário dar suporte aos profissionais e proporcionar-lhes constante supervisão, a fim de criar um espaço de diálogo entre a equipe, que possibilite a redução da angústia e impotência que sentem.

\section{Processo de acolhimento}

Apesar da não privação da liberdade no caso da aplicação de medidas de proteção, foi percebido, nas observações de campo, que aos adolescentes só é permitida a saída da UA para ir à escola, estágio, cursos e eventuais atividades programadas pela instituição, quase sempre na companhia de um educador social. Poucos têm a chance de ir aos lugares citados sozinhos. O critério utilizado para que isso aconteça, geralmente, é o de merecimento por bom comportamento e cumprimento de regras. Além disso, os horários são bem restritos. Os adolescentes devem voltar no horário estipulado pela UA, não tendo tempo para fazer coisas simples e naturais ao seu desenvolvimento como conversar com os colegas de escola na hora da saída, tendo um momento de lazer desvinculado das imposições da instituição. A participação na vida da comunidade local, prevista no artigo 92 do ECA (Lei Federal 8.069,1990), fica limitada apenas às obrigações diárias e atividades esporádicas de lazer, não havendo uma participação de fato dos adolescentes na vida comunitária: 
Lá, o educador acompanha você em tudo. Leva no colégio, busca, leva no curso, leva no programa lá que eles botam pra fazer. Por isso que veio na minha cabeça que eu tinha que sair de lá. Lá é muito rigoroso, muitas regras. (Lucas, 16 anos, UA2)

Por trás dessa vigilância constante se encontra, também, o receio do profissional, especialmente dos educadores sociais, que acompanham os adolescentes nas atividades, em dar a liberdade que lhes é garantida por lei, temendo, no fundo, sua evasão. E, como já foi apontado anteriormente, o "fantasma" constante da evasão significa, para muitos, a anulação de todas as conquistas advindas com seus esforços no cotidiano laboral. Nesse sentido, a prática aproxima-se da medida de privação de liberdade, a fim de assegurar a permanência dos adolescentes.

Adicionalmente, certas rotinas, como a revista no adolescente quando volta da rua para verificar se traz consigo coisas proibidas, como drogas, parecem mais comprometidas com a proposta do recolhimento, e demonstram que as relações entre profissionais e adolescentes, que deveriam ter como princípio o diálogo e a confiança, não ocorrem dessa forma, o que desperta conflito nos profissionais:

A gente tem uma coisa de tratar como cidadão, de fazer um trabalho de integrar esse jovem, de fazer uma proposta diferenciada na vida dele, de ter uma acolhida, um acolhimento. E você viola isso? Aí você tá desrespeitando um pacto que você faz com aquela pessoa e com as próprias regras de trabalho. Se aqui não é um regime de internação, se a gente não quer criminalizar a pobreza, se não quer tratar o jovem morador de rua como jovem infrator, então, essa regra da revista é contraditória. (Diva, assistente social, UA1)

Mesmo que procedimentos de controle e de disciplinamento aconteçam de modo implícito, o adolescente percebe-se aprisionado, condição antagônica àquela que ele vivia quando se encontrava em situação de rua. Isso reforça a percepção deles de que o viver nas ruas representa liberdade:

Na hora do almoço não pode ficar no quarto, acorda e ele fica trancado o dia todo. Só vai voltar pro quarto de noite no horário de dormir, que são dez horas. A gente almoça, tá com sono, às vezes quer dormir, deitar um pouco pra dormir, não pode. Tem que deitar num banco lá fora ou no chão pra dormir, não pode entrar no quarto, porque ele fica trancado. Só abre o quarto pra você pegar uma roupa, ou alguma coisa pra você tomar um banho. (Ursula, 16 anos, UA3)

O próximo entrevistado questiona o próprio funcionamento do sistema, que não consegue cessar o ciclo de entrada e saída:
Isso de evadir e ficar voltando toda hora é muito ruim! Têm uns três ou quatro meninos que já evadiram mais de 10 vezes; eles vão ... voltam. É porque os que tão na perca do final de semana, são aqueles que tão bem bagunceiro mesmo! Aí, eles vão, pulam: "A gente pula de manhã e de tarde a gente volta”. É assim que eles pensam! (José, educador social, UA1)

No cotidiano das UAs, os cuidadores estão permanentemente buscando alternativas para evitar a evasão. O ócio é visto por eles como um fator prejudicial à permanência dos adolescentes. Por isso, esforçam-se para combatê-lo preenchendo o dia do adolescente por completo:

O trabalho, eu acredito que já estou tentando fazer: é atividade em cima de atividade. Nunca deixar esse garoto com a mente solta pra ficar pensando em 'as' e 'bs'. Nós temos que estar fazendo isso, não só ocupando o menino, mas também o educador, a todo o momento. Porque a hora passa e, quando você vê, você quer mais tempo pra trabalhar, e já acabou o tempo! Quando ele está à toa, ele tem tempo pra pensar: pensar em fugir, pensar em fazer isso com o coleguinha, pensar nas coisas ruins da sua vida. (Rubia, educadora social, UA2)

O profissional frisa que as atividades devem ocupá-los, ou melhor, entretê-los (Sarraceno, 1996) todo o tempo, porém, esta prática não assegura a permanência dos adolescentes, que precisam de uma rotina com atividades que promovam vínculos mais sólidos na instituição e não atividades com o objetivo de distraí-los. Faz-se importante que parte dessas atividades ocorra fora dos muros das UAs, o que não implica necessariamente em evasão, fortalecendo a participação na comunidade, fundamental para o desenvolvimento dos adolescentes.

Outra forma de tentar manter o adolescente tem sido apelar para a argumentação em torno das perdas materiais que ele virá a ter. Algumas vezes os cuidadores conseguem persuadi-lo a ficar, no entanto, tais recursos não são os métodos mais adequados de lidar com a situação:

Eu não posso segurar eles, nem puxar, tem que conversar com eles: "Pô, não vai por aí. Vamo levar doutra forma, lá fora vocês não têm um lanche, não têm um almoço, não têm uma janta, não têm uma cama pra dormir, não têm uma televisão pra assistir". Uns até aceitam essa minha conversa! Enfim, outros não... Se eu seguro, pra eles eu tô agredindo, tô batendo. (Silvio, equipe de apoio, UA1)

Os exemplos citados demonstram que muitos profissionais não compreendem o significado do binômio evasão/acolhimento. 
Verificou-se nas UAs pesquisadas a necessidade de ocupar o tempo dos adolescentes, entretê-los, como uma estratégia dos profissionais para diminuir as angústias que o processo de acolhimento desperta em todos. Há que se evitar o "tempo ocioso", o tempo para pensar, para sofrer, para se revoltar ou silenciar. Com efeito, a estratégia geralmente é tentar manter suas mentes e corpos ocupados para que todos nas UAs consigam resistir, aguentar e suportar, pois, em última análise, eles lidam de frente com um dos subprodutos da sociedade que despeja ali seu lixo social (Bauman, 1998).

Nas observações de campo, ficou evidente para a equipe da pesquisa que as idas e vindas dos adolescentes causam, não só um prejuízo ao desenvolvimento de um acompanhamento contínuo, como também um desgaste muito grande por conta de toda a burocracia envolvida nas guias de desligamento e acolhimento todas as vezes que ocorre evasão/retorno. Como isso acontece com grande frequência, há um dispêndio de tempo da equipe técnica entrevistada nas duas UAs nessas tarefas burocráticas que, para eles, toma parte do espaço que deveria ser usado com os adolescentes:

Eu acho que essa parte burocrática pesada. Me toma muito tempo. Têm horas que eu tenho que fechar a porta, senão não consigo trabalhar, e isso acaba me afastando um pouco do dia a dia, da relação com os meninos. Assim: 'Agora, não dá não!' 'Tá ocupada?' 'Tô ocupada, mais tarde a gente conversa'. Às vezes, têm meninos que quer conversar naquela hora, naquele momento e, muitas vezes, você acaba perdendo o 'pulo do gato'. Porque não pode dar essa atenção. (Vitória, assistente social, UA2)

Além disso, a evasão não significa, necessariamente, abandono ou rompimento com a UA. Geralmente, ela é parte do processo de experimentação de limites e possibilidades dos acolhidos:

Olha, a gente tá com uma baixa evasão, graças a Deus. Já tivemos épocas de ter muitas evasões, que tinha muitos meninos que não queriam ser ajudados. Ainda têm uns que não querem. A gente sabe que os meninos tão se conscientizando de que precisam de ajuda. E isso tem fortalecido muito o trabalho da gente também. Porque, às vezes, a gente trabalha tanto e, de repente, o rapaz tinha uma recaída, "voltava tudo à estaca zero”. (Irene, educadora social, UA2)

$\mathrm{Na}$ realidade, é importante que os cuidadores compreendam que nesse processo de acolhimento nunca se volta à 'estaca zero' ou anula-se tudo o que foi desenvolvido com aquele adolescente após uma evasão. Porém, nessas UAs, quando ela ocorre, ao invés de ser vista como parte inerente ao processo, ainda converte-se em um problema a ser evitado.
A equipe precisa, para abrir mão do senso comum, exercitar sua capacidade de reflexão sobre aquilo que é preconizado como o certo ou o errado, além de valores socialmente construídos, expandindo seu entendimento para a realidade do adolescente, levando em conta os desejos, pensamentos e perspectivas dele. Com isto pode-se criar um espaço para que suas vozes sejam acolhidas a partir de uma escuta desarmada, atenta às expressões de suas subjetividades.

Para o adolescente, o abrigamento pode ser visto, muitas vezes, como equivalente ao aprisionamento, e a experiência da liberdade nas ruas pode ser mais importante do que uma cama limpa ou um prato quente de comida. Cabe ao cuidador o manejo dessa situação, na qual há objetivos e pontos de vista distintos, além de o tempo dos atores ser diferente. $\mathrm{O}$ adolescente é imediatista, e isso esbarra nas propostas de trabalho pensadas a médio e longo prazo. É importante que os profissionais aproveitem o tempo que têm com eles, focando na qualidade dessa relação, independente de quanto tempo ela durar. No tempo em que o adolescente estiver na UA, deve-se estabelecer um foco personalizado, adequando as ações educativas às peculiaridades da adolescência. Ademais, deve-se incentivar a tomada de responsabilidade e autonomia dele.

Embora seja frustrante lidar com as constantes mudanças produzidas no processo de acolhimento, tais experiências são geradoras de aprendizagem, transformação e crescimento para todos os envolvidos, sobretudo se forem devidamente elaboradas com um trabalho de capacitação e supervisão, que pode gerar um entendimento da evasão como parte do processo de acolhimento.

\section{Conclusão}

Através do que foi apresentado, pôde-se concluir que os princípios definidos pelo ECA para o funcionamento das UAs não são plenamente cumpridos devido a uma série de questões. Dentre elas, estão os problemas administrativos da rede de Assistência Social, que não respalda de maneira adequada o desenvolvimento do trabalho dos profissionais. Além das dificuldades em lidar com as evasões, diversos outros acontecimentos cotidianos do adolescente não são superados, principalmente porque os cuidadores não estão capacitados para esse tipo de intervenção junto aos adolescentes com os quais trabalham.

A falta de capacitação e supervisão dos profissionais afeta o processo de acolhimento e também causa sofrimento psíquico aos cuidadores. Com efeito, por não conseguirem manejar bem algumas situações, ficam frustrados e desmotivados com seu 
trabalho. Já os adolescentes não criam vínculos com os profissionais, percebendo-os muitas vezes como figuras repressoras, preferindo as ruas, onde acreditam que podem ser livres.

Os profissionais precisam ser preparados para perceberem a diferença, na prática cotidiana, entre o recolhimento e o acolhimento, assimilando uma visão mais clara acerca dos significados da evasão, para acolherem de fato os adolescentes.

É preciso que a equipe das UAs desenvolva um trabalho consistente e integrado em torno dos verdadeiros objetivos do acolhimento, sendo amparada por uma rede atuante que lhe dê suporte. Faz-se necessário, também, maior investimento na realização de projetos, para a capacitação e supervisão dos profissionais. $\mathrm{O}$ cuidador precisa ser auxiliado por uma estrutura consistente e que lhe dê autoridade perante o adolescente, senão ele acaba oscilando entre ter uma postura autoritária, permissiva ou negligente, sentindo-se perdido em seu trabalho.

$\mathrm{O}$ processo de acolhimento institucional tornase mais atrativo do que as ruas na medida em que os profissionais constroem junto ao adolescente um ambiente continente, onde este se sinta respeitado em sua singularidade, protegido e possa traçar um projeto de vida para além da UA.

É de extrema importância achar um meio termo para que aqueles que trabalham nas UAs se sintam "acolhidos" para poder acolher, de fato, os adolescentes, propiciando qualidade de vida e possibilidades para o futuro.

\section{Referências}

Alberti, V. (2004). Ouvir Contar. Rio de Janeiro: FGV.

Andrade, A. N. \& Morato, H. T. P. (2004). Para uma dimensão ética da prática psicológica em instituições. Estudos de Psicologia (Natal), 9(2). Acesso em 21 de fevereiro, 2014, em http://www.scielo.br/scielo.php?script=sci arttext\&pid=S1413-294X2004000200017

Bauman, Z. (1998). O mal-estar da pós-modernidade. Rio de Janeiro: Jorge Zahar.

Boudon, P. (1998). L'abduction et le camp sémiotique. In G. Brunel (Ed.), Le tiers communicationnel (pp. 255-284). Montreal: L'Harmattan.

Castel, R. (1998). As metamorfoses da questão social: uma crônica do salário. Petrópolis, RJ: Vozes.

Conselho Nacional de Defesa da Criança e do Adolescente CONANDA \& Conselho Nacional de Assistência Social - CNAS. (2009). Orientações técnicas para os serviços de acolhimento para crianças e adolescentes. Acesso em 18 de fevereiro, 2014, em http://portal.mj.gov.br/sedh/conanda/ documentos/orienta $\% \mathrm{C} 3 \% \mathrm{~A} 7 \% \mathrm{C} 3 \% \mathrm{~B} 5$ es acolhimento consulta publica.pdf

Costa, J. F. (2010). O ponto de vista do outro. Rio de Janeiro: Garamond.
Esteves, M. A. (1989). Meninas perdidas: os populares e o cotidiano do Amor no Rio de Janeiro da Belle Époque. Rio de Janeiro: Paz e Terra.

Foucault, M. (1984). Vigiar e punir. Petrópolis, RJ: Vozes. (Original publicado em 1977).

Lei Federal $n^{\circ} 8.069$ de 13 de julho de 1990. Estatuto da Criança e do Adolescente - ECA. Brasília, DF: Ministério da Justiça. Acesso em 25 julho, 2011, em http://www.planalto.gov.br/ ccivil 03/leis/L8069.htm

Lozano, J. E. A. (2006). Práticas e estilos de pesquisa na história oral contemporânea. In M. Ferreira e J. Amado (Orgs.), Usos e abusos da História Oral (pp. 15-25). Rio de Janeiro: FGV.

Minayo, M. C. S. (2006). O desafio do conhecimento: pesquisa qualitativa em saúde. São Paulo: Hucitec.

Rio, J. (2007). A almaencantadora das ruas. Minas Gerais: Crisálida. (Original publicado em 1908)

Sarraceno, B. (1996). Reabilitação psicossocial: uma estratégia para a passagem do milênio. In A. Pitta (Org.), Reabilitação psicossocial no Brasil (pp. 13-18). São Paulo: Hucitec.

Thompson, P. (1992). A voz do passado: História oral. Rio de Janeiro: Paz e Terra.

\section{Agradecimento}

Ao CNPq, pelo apoio. Edital $n^{0} 33 / 2008$ Processo 575272/2008-2.

Submissão em: 20/06/2012

Revisão em: 11/02/2014

Aceite em: 01/04/2014

Adriana Guerra Abreu Lemos é graduada em Psicologia (UFRJ). Endereço: Instituto de Psiquiatria da Universidade Federal do Rio de Janeiro. Avenida Venceslau Brás, 71, Fundos. Botafogo. CEP: 22290-140. Rio de Janeiro/RJ, Brasil. E-mail: adriana ablemos@hotmail.com

Mayara Cristina Muniz Bastos Moraes é psicóloga, mestranda em Psiquiatria e Saúde Mental pelo Instituto de

Psiquiatria da Universidade Federal do Rio de Janeiro. E-mail: mayacmoraes@gmail.com

Daniel Gonçalves Alves é graduando em Psicologia pelo Centro Universitário Augusto Motta. E-mail: danielalvesdga@gmail.com

Elizabeth Espindola Halpern é PhD em Saúde Mental pelo Instituto de Psiquiatria da Universidade Federal do Rio de Janeiro. E-mail: espindolahalpern@yahoo.com.br

Ligia Costa Leite é pesquisadora professora colaboradora do Instituto de Psiquiatria da Universidade Federal do Rio de Janeiro. E-mail: ligia.cleite@gmail.com

\section{Como citar:}

Lemos, A.G.A., Moraes, M.C.M.B., Alves, D.G., Halpern, E. E., \& Leite, L. C. (2014). Evasão nas unidades de acolhimento: discutindo seus significados Psicologia \& Sociedade, 26(3), 594-602. 